\title{
Processos evolutivos e a origem das plantas cultivadas
}

\author{
Evolutionary processes and the origin of crop plants
}

\author{
Elizabeth Ann Veasey ${ }^{\mathrm{I}}$ Fernando Angelo Piotto $^{\mathrm{I}}$ Wellington Ferreira do Nascimento ${ }^{\mathrm{I}}$ \\ Jucelene Fernandes Rodrigues ${ }^{\mathrm{I}}$ Thiago Fonseca Mezette $^{\mathrm{I}}$ Aline Borges $^{\mathrm{II}}$ Felipe Almeida Biguzzi ${ }^{\mathrm{II}}$ \\ Fernanda Raquel Camilo dos Santos ${ }^{\text {III }}$ Graciela da Rocha Sobierajski ${ }^{\text {IV }}$ Gustavo Henrique Recchia ${ }^{\mathrm{II}}$ \\ Julio César Mistrov
}

\section{- REVISÃo BIBLIOGRÁFICA -}

\section{RESUMO}

A evolução das plantas cultivadas, que teve início há cerca de 13.000 anos, está sujeita aos mesmos processos evolutivos naturais, aliada à ação do homem de forma consciente ou inconsciente, levando à domesticação. Nesta revisão, são apresentados os principais fatores evolutivos, tais como mutação, hibridação, migração, seleção e deriva genética, que, de alguma maneira, estão envolvidos com a origem, evolução e domesticação de plantas cultivadas. São apresentados também exemplos de como esses processos influenciaram na diversidade intra e interespecifica de plantas cultivadas, com o aparecimento de novas variedades ou mesmo de novas espécies. De modo geral, tais processos atuaram na ampliação, na manutenção, bem como na redução da variabilidade genética das plantas cultivadas.

Palavras-chave: domesticação de plantas, mutação, hibridação, migração, seleção, deriva genética.

\section{ABSTRACT}

The evolution of crop plants, which began at about 13,000 years ago, is subject to the same natural evolutionary processes, coupled with the action of man, consciously or unconsciously, leading to domestication. This review presents the main evolutionary factors such as mutation, hybridization, migration, selection and genetic drift, which somehow are involved in the origin, evolution and domestication of crop plants. Examples of how these processes influenced in the intra and interespecific diversity of crop plants, with the uprise of new varieties or even of new species, are also presented. In general, these processes have worked well in the increase, maintenance, as well as in the reduction of genetic diversity of crop plants.

Key words: plant domestication, mutation, hybridization, dispersion, selection, genetic drift.

\section{INTRODUÇÃO}

No Pleistoceno recente, pouco mais de 10,000 anos a.C., as primeiras populações humanas se organizaram numa sociedade de caçadores e coletores antes de iniciarem a prática agrícola no período Neolítico (DIAMOND \& BELLWOOD, 2003). Estas eram caracterizadas por se deslocarem com maior frequência, realizando o manejo dos recursos naturais, protegendo espécies de interesse, podendo ainda alterar a densidade e distribuição de espécies (BELLWOOD, 2005).

\footnotetext{
'Departamento de Genética, Escola Superior de Agricultura "Luiz de Queiroz" (ESALQ), Universidade de São Paulo (USP). Av. Pádua Dias, 11, 13400-970, Piracicaba, SP, Brasil. E-mail: eaveasey@esalq.usp.br. *Autor para correspondência.

"Centro de Energia Nuclear na Agricultura, Universidade de São Paulo (CENA/USP), Piracicaba, SP, Brasil.

IIICentro de Pesquisa e Desenvolvimento em Recursos Genéticos Vegetais, Instituto Agronômico/Agência Paulista de Tecnologia dos Agronegócios (IAC/APTA), Campinas, SP, Brasil.

${ }^{\mathrm{IV}}$ Centro APTA Frutas, IAC/APTA, Jundiaí, SP, Brasil.

${ }^{\vee}$ Centro de Café - IAC/APTA, Campinas, SP, Brasil.
} 
Com o advento da agricultura, considerada como um pré-requisito para o surgimento das civilizações, acompanhada de uma grande transformação demográfica global (DIAMOND, 2002), iniciou-se o processo de domesticação de plantas cultivadas, sob a ação dos mesmos processos evolutivos que ocorreram ao longo da evolução das plantas em geral (LADIZINSKY, 1998). O diferencial, no entanto, foi a ação do homem, que, de forma consciente ou inconsciente, acabou tornando-as dependentes da interferência humana e dos ambientes criados por ele (FULLER, 2007).

Uma das consequências do processo de domesticação de plantas cultivadas foi o surgimento das 'síndromes de domesticação', ou seja, um conjunto de caracteres que distinguem as plantas cultivadas dos seus ancestrais selvagens (FULLER, 2007; BROWN et al., 2009). O resultado foi o surgimento de inúmeras novas variedades de diferentes espécies de plantas ou mesmo o surgimento de novas espécies, resultando num aumento da variabilidade genética, enquanto que em outros casos o resultado foi uma diminuição da variabilidade genética, como se observa, por exemplo, no processo de seleção associado ao melhoramento genético de plantas, ou em função da atuação da deriva genética. Já em alguns casos, o resultado foi a manutenção da variabilidade genética (LADIZINSKY, 1998).

Nesta revisão, foram abordados os principais processos evolutivos que atuaram durante a evolução e domesticação de plantas cultivadas.

Mutação

A mutação, um dos fatores evolutivos que geram variabilidade genética, é definida como qualquer alteração na sequência de nucleotídeos, bem como na estrutura e número de cromossomos (FUTUYMA, 2006). Essas alterações, que podem ocorrer espontaneamente na célula ou pela ação de substâncias mutagênicas, radiações ionizantes e ultravioletas, causam substituições errôneas de bases nitrogenadas e alterações numéricas ou estruturais nos cromossomos.

Mutações nos genes relacionados às características de interesse agronômico podem ter facilitado a domesticação de algumas espécies de plantas cultivadas, principalmente em gramíneas, como trigo, arroz emilho (LADIZINSKY, 1998). Essas culturas, a partir de várias mutações gênicas, adquiriram maior capacidade de retenção dos grãos na inflorescência tornando-as mais dependentes da ação humana para sua dispersão. Assim como as gramíneas, a uva (Vitis vinifera) também sofreu diversas modificações relacionadas à produção de frutos durante a sua domesticação. Com o intuito de estudar a produção de antocianina, principal responsável pela coloração dos frutos da uva, THIS et al. (2007) analisaram a variação do gene $V v m y b A$ em 200 acessos de uva e verificaram que a inserção do elemento Gretl na região promotora permitiu o surgimento da coloração vermelha nos frutos (Tabela 1).

$\mathrm{Na}$ geração $\mathrm{F}_{3}$ de um cruzamento entre cebolas (Allium cepa) de coloração amarela, indivíduos mutantes de coloração dourada foram identificados. KIM et al. (2004) verificaram a presença de um códon de terminação pré-maturo e adição de bases na região que codifica a enzima Chalcone isomerase (CHI). Essa mutação resultou na inativação do gene $C H I$, bloqueando a síntese de flavonóides e gerando um acúmulo de derivados da Chalcone, culminando na produção de uma cebola dourada. Em arroz, a deleção do gene $q S W 5$, responsável pelo controle do número de células nas glumas e largura do grão, causou um aumento na produção de sementes, favorecendo a seleção artificial dessas variedades pelos primeiros agricultores durante a domesticação da espécie (SHOMURA et al., 2008). Na cultura do trigo (Triticum aestivum), cromossomos não pareados, quebrados ou perdidos, são anomalias cromossômicas bastante observadas, o que dificulta a manutenção de linhagens homozigotas. Essa instabilidade genética, geralmente deletéria para outras culturas, na maioria das vezes não provoca a morte das plantas de trigo devido ao seu caráter hexaplóide $(2 \mathrm{n}=6 \mathrm{x}=42)$ (FERNANDES et al., 1991).

Como a mutação espontânea ocorre com baixa frequência na natureza, a técnica de indução utilizando agentes mutagênicos químicos e físicos tem sido bastante empregada, visando obter mutações promissoras tanto para o melhoramento genético, como para obtenção de variantes importantes para o estudo de função gênica. ISHIY et al. (2006) identificaram uma nova variedade de arroz, SCS Andosan 114, progênie mutante da cultivar 'IR 840' após o tratamento com $150 \mathrm{~Gy}$ de radiação gama. A nova variedade mostrou-se mais produtiva e com maior teor de amido no grão, além da maior tolerância a doenças e toxidez por ferro. KIKUCHI et al. (2009), avaliando o efeito de diferentes fontes de irradiação em trigo, observaram que elas geraram recombinações não deletérias, aumentando artificialmente a taxa de recombinações nesta cultura.

Em programas de melhoramento de diversas culturas, existem centenas de eventos bem sucedidos do uso de mutagênese, como, por exemplo, a indução de mutantes em laranja (Citrus sinensis) para redução do número de sementes (LATADO et al., 2001), modificações na arquitetura da planta e caracteres 
Tabela 1 - Consequências dos processos evolutivos na origem e domesticação de plantas cultivadas.

\begin{tabular}{|c|c|c|c|}
\hline $\begin{array}{l}\text { Processos } \\
\text { evolutivos }\end{array}$ & Culturas & Consequências & Autores \\
\hline \multirow[t]{7}{*}{ Mutação } & Arroz & Surgimento de novas variedades de arroz. & SHOMURA et al., 2008; ISHIY et al., 2006. \\
\hline & Cebola & Surgimento de bulbos brancos, amarelos e vermelhos. & KIM et al., 2004. \\
\hline & Laranja & Redução do número de sementes. & LATADO et al., 2001. \\
\hline & Pêra & Modificação de caracteres ligados à produção de frutos. & PREDIERI \& ZIMMERMAN, 2001. \\
\hline & Tomate & Obtenção de mutantes para estudos de função gênica. & PINO-NUNES et al., 2009. \\
\hline & Trigo & Surgimento de recombinantes. & $\begin{array}{l}\text { FERNANDES et al., 1991; KIKUCHI et al., } \\
2009 .\end{array}$ \\
\hline & Uva & Variação da coloração vermelha. & THIS et al., 2007. \\
\hline \multirow[t]{7}{*}{ Hibridação } & Algodão & Origem de novas espécies tetraplóides. & KIMBER, 1961. \\
\hline & Arroz & Fluxo gênico entre arroz transgênico e arroz selvagem. & LU \& YANG, 2009. \\
\hline & Café & Origem de uma nova espécie tetraplóide. & LÓPEZ-GARTNER et al., 2009. \\
\hline & Mandioca & Fluxo gênico da espécie cultivada e parental selvagem. & DUPUTIÉ et al., 2007. \\
\hline & Milho & Fluxo gênico da espécie cultivada e parental selvagem. & MATSUOKA et al., 2002. \\
\hline & Trigo & $\begin{array}{l}\text { Hibridação entre três espécies produzindo o trigo comum } \\
\text { por alopoliploidia. }\end{array}$ & BRAMMER et al., 2001. \\
\hline & Batata & Obtida por autopoliploidia. & SPOONER et al., 2007. \\
\hline \multirow[t]{7}{*}{ Dispersão } & Abacate & Dispersão natural de sementes por mamíferos. & $\begin{array}{l}\text { CHANDERBALI et al., 2001; WEIRSUM, } \\
1997 .\end{array}$ \\
\hline & Algodão & Dispersão da América para outros continentes. & HOVAV et al., 2008. \\
\hline & Batata & Dispersão e surgimento de novos ecótipos. & BURTON, 1966. \\
\hline & Café & Dispersão da Etiópia para o novo mundo. & ANTHONY et al., 2002. \\
\hline & Feijão comum & Dispersão da América para outros continentes. & PAPA et al., 2004. \\
\hline & Oliveira & Dispersão para diversas regiões do mundo. & BRETON et al., 2009. \\
\hline & Pimentões & Dispersão da América para outros continentes. & AGUILAR-MELÉNDEZ et al., 2009. \\
\hline \multirow[t]{4}{*}{ Seleção } & Arroz & $\begin{array}{l}\text { Mudança no tamanho, forma e conteúdo de amilose do } \\
\text { grão. }\end{array}$ & KOVACH et al., 2007. \\
\hline & Aveia & Aumento do teor de proteína. & MATIELLO et al., 1997. \\
\hline & Milho & Dificuldade na dispersão natural da semente. & DOEBLEY et al., 2006. \\
\hline & Tomate & Aumento no tamanho do fruto. & FRARY et al., 2000. \\
\hline Deriva & Algodão & Estreitamento da base genética. & IQBAL et al., 2001. \\
\hline \multirow[t]{6}{*}{ Genética } & Arroz & Estreitamento da base genética. & KOVACH \& McCOUCH, 2008. \\
\hline & Café & Estreitamento da base genética. & LÓPEZ-GARTNER et al., 2009. \\
\hline & Milho & Perda de diversidade genética. & EYRE-WALKER et al., 1998. \\
\hline & Soja & Estreitamento da base genética. & HYTEN et al., 2006. \\
\hline & Tomate & Estreitamento da base genética. & SAN-SAN-YI et al., 2008. \\
\hline & Trigo & Estreitamento da base genética. & REIF et al., 2005. \\
\hline
\end{tabular}

ligados à produção de frutos em pêra (Pyrus communis) (PREDIERI \& ZIMMERMAN, 2001) e obtenção de mutantes para estudos fisiológicos e função gênica em tomateiro (Solanum lycopersicum) (PINO-NUNES et al., 2009), dentre outros.

Hibridação e fluxo gênico

Dentre todos os fatores evolutivos, a hibridação natural, definida como acasalamento natural entre indivíduos de duas ou mais populações, é um dos eventos de maior importância evolutiva (ARNOLD, 2004). Diversos estudos têm demonstrado os seus efeitos ao longo do processo de domesticação das plantas cultivadas, envolvendo fluxo gênico entre espécies selvagens e cultivadas (DUPUTIÉ et al., 2007), envolvendo também a introgressão de culturas geneticamente modificadas (DALTON, 2009) e a especiação híbrida (MALLET, 2007).

Diversos trabalhos têm demonstrado a ocorrência de fluxo gênico entre espécies cultivadas e 
seus parentais selvagens. MATSUOKA et al. (2002), avaliando o fluxo gênico entre variedades de milho e seu parental selvagem, o teosinto (Zea mays ssp. mexicana), observaram que esse mecanismo afetou a estrutura genética das variedades cultivadas, possibilitando a sua sobrevivência em ambientes extremos, como elevadas altitudes. Por outro lado, o fluxo gênico da planta domesticada para seu parental selvagem pode reduzir sua aptidão e comprometer sua persistência em seu habitat natural, além de causar a desestruturação genética do táxon e sua extinção, já que o híbrido originado pode apresentar heterose e competir com as formas selvagens (ELLSTRAND et al., 1999). DUPUTIÉ et al. (2007) avaliaram a possível ocorrência de uma zona híbrida entre a mandioca cultivada (Manihot esculenta) e um parental selvagem (Manihot ssp.) e observaram a ocorrência de híbridos naturais que comparados aos seus parentais apresentaram heterose. Esse tipo de situação é preocupante quando se considera a questão da conservação das espécies selvagens, já que a ocorrência de fluxo gênico da planta cultivada para o seu progenitor selvagem pode levar ao aparecimento de plantas daninhas mais agressivas (MAGNUSSEN \& HAUSER, 2007) ou a introdução de genes da planta cultivada no genoma da espécie selvagem, que poderia levar à extinção das populações selvagens por mistura completa (ELLSTRAND et al., 1999).

A preocupação com a conservação dos recursos genéticos vegetais é ainda maior com o surgimento das plantas transgênicas, já que a ocorrência de fluxo gênico pode afetar a organização da diversidade genética das variedades cultivadas e/ ou dos parentes silvestres. A verificação do fluxo gênico entre espécies que apresentam a forma transgênica é importante para inferir a possibilidade de trocas de alelos que representam uma ameaça para a preservação dos tipos selvagens (GEPTS \& PAPA, 2003). Em uma revisão sobre o tema, LU \& YANG (2009) avaliaram vários estudos de fluxo gênico entre espécies de arroz selvagem e transgênico e concluíram que o escape destes para populações selvagens ou daninhas pode representar consequências ecológicas em potencial.

A especiação híbrida é aquela em que a hibridação teve um importante papel na formação de uma nova espécie (MALLET, 2007). Em geral, uma nova espécie é formada quando duas delas se cruzam e o genoma do híbrido é duplicado, formando um alopoliplóide. Esse processo pode se repetir de modo a formar espécies com mais de dois genomas diferentes. Diversos exemplos de alopoliplóides são descritos na literatura, entre eles o caso do trigo (Triticum aestivum), formado por três genomas distintos (AABBDD), originário do cruzamento entre $T$. monococcum (AA), T. searssi (BB), sendo que o híbrido $F_{1}$ teve o seu número de cromossomos duplicados, formando o $\boldsymbol{T}$. turgidum (AABB) que se hibridizou com o T. tauschii (DD) (BRAMMER et al., 2001). Outras espécies de plantas cultivadas que sofreram o mesmo mecanismoé o algodão tetraplóide (Gossypium hirsutum e $\boldsymbol{G}$. barbadense), formado a partir do cruzamento de uma espécie diplóide (genoma A) originária da Ásia com outra espécie diplóide (genoma D) originária do Novo Mundo (KIMBER, 1961); e também o café tetraplóide (Coffea arabica), originário do cruzamento entre as espécies Coffea eugenioides e C. canephora (LÓPEZGARTNER et al., 2009), entre outros (Tabela 1).

Contudo, além da alopoliploidia na especiação híbrida, os autopoliplóides também tiveram um papel muito importante na evolução das plantas cultivadas, pois o efeito "giga" proporcionado pelo aumento no número de cópias dos cromossomos em uma mesma célula ajudou o homem a selecionar plantas com raízes, tubérculos, caules, folhas, frutos e sementes maiores. No entanto, este processo tem sido associado a uma redução na fertilidade devido a problemas no pareamento da meiose, o que explica o fato da autopoliploidia espontânea estar mais associada às plantas de reprodução vegetativa, ou àquelas em que as partes vegetativas são utilizadas (LADIZINSKY, 1998). Na história da domesticação das plantas, alguns autopoliplóides merecem destaque, como é o caso da batata (Solanum tuberosum), a qual pode ser diplóide $(2 \mathrm{n}=2 \mathrm{x}=24)$, triplóide $(2 \mathrm{n}=3 \mathrm{x}=36)$, tetraplóide $(2 \mathrm{n}=4 \mathrm{x}=48)$ e até pentaplóide ( $2 \mathrm{n}=5 \mathrm{x}=60)$ (SPOONER et al., 2007). Podemos citar também os poliplóides induzidos, como é o caso do autotetraplóide artificial de melancia (Citrullus vulgaris) com $2 \mathrm{n}=4 \mathrm{x}=44$ cromossomos (JASKANI et al., 2004), o qual tem sido utilizado em cruzamentos com linhagens diplóides $(2 n=2 x=22)$ para obtenção de híbridos triplóides $(2 \mathrm{n}=3 \mathrm{x}=33)$ sem sementes.

\section{Dispersão, migração e colonização}

A dispersão dos organismos se constitui em dois importantes fenômenos, a migração e a colonização (HAMARICK \& NASON, 1996). Esses fatores contribuem para a ocorrência de fluxo gênico, permitindo que outros mecanismos, tais como hibridação, deriva genética e seleção natural, possam atuar no processo de adaptação e especiação. Em espécies cultivadas, mudanças adaptativas podem ocorrer devido à pressão de seleção, bem como adaptação a diferentes práticas de cultivo às quais são submetidas, quando introduzidas em áreas com 
condições edafoclimáticas diferentes daquelas apresentadas em seus centros de origem, diversidade ou domesticação. A cultura da batata (Solanum tuberosum), levada da América do Sul à Europa, sofreu restrições ao florescimento devido ao fotoperíodo do Velho Mundo, com dias mais longos. No entanto, com o conhecimento da importância desse fator, a batata pôde ser explorada, permitindo a ocorrência da troca de sementes entre os agricultores e o surgimento de uma nova diversidade de ecótipos, adaptados aos dias mais longos (BURTON, 1966).

A história da ocupação e deslocamento humano pelos continentes também foram decisivos para o surgimento das espécies domesticadas. $\mathrm{O}$ abacate (Persia americana), por exemplo, que teve seu ancestral disperso durante a era glacial no Pleistoceno, chegando a atingir a Mesoamérica através da movimentação de grandes mamíferos e dispersão natural das sementes, foi domesticado após a chegada do homem à América, por volta de 8000 a 7000 a.C. (CHANDERBALI et al., 2001). Posteriormente, o abacate teria sido levado ao sul do continente acompanhando as rotas de colonização humana précolombiana (WEIRSUM, 1997). Em eventos mais recentes de dispersão, a cultura foi levada a outros continentes, predominantemente pelos colonizadores europeus, assim como ocorreu nos séculos 16 e 17 com diversas culturas também originadas na América, tais como o feijão comum (Phaseolus vulgaris) (PAPA et al., 2004), pápricas e pimentões (Capsicum annuum) (AGUILAR-MELÉNDEZ et al., 2009), amendoim (Arachis hypogaea) (WILLIAM, 2004) e algodão (Gossypium hirsutum) (HOVAV et al., 2008) (Tabela 1). Outro exemplo que podemos citar é a cultura do abacaxi (Ananas comosus), originário da América tropical e subtropical e, muito provavelmente, do Brasil (MEDINA et al., 1978; CRESTANI et al., 2010), sendo disperso para vários países americanos pelo intercâmbio entre tribos, e tendo sido levado para a Europa, Ásia e África após o descobrimento da América, disseminando-se rapidamente pelos países desses continentes (CTENAS \& QUAST, 2000).

Dados moleculares têm sido eficientes ferramentas para o estudo da origem e domesticação de espécies cultivadas (BROWN et al., 2009). Marcadores microssatélites foram fundamentais para definirem a ocorrência de locais distintos de domesticação da oliveira (Olea europaea subsp. europaea), resultantes de eventos de fluxo gênico da espécie selvagem associado à migração humana. A espécie selvagem de oliva, domesticada na região do Oriente Médio, Norte da África e oeste da Europa, foi levada pelo homem para diversas regiões do mundo com clima Mediterrâneo (África, Austrália, Ásia e América) (BRETON et al., 2009). Na cultura do café (Coffea arabica), foi possível entender os eventos de seleção negativa e deriva genética, que resultaram no estreitamento da base genética da espécie, constituindo apenas dois conjuntos gênicos bem definidos originários de duas subpopulações selvagens do sudoeste da Etiópia (ANTHONY et al., 2002).

Eventos recentes de dispersão podem ser relacionados com a troca de material vegetal entre áreas agriculturáveis. Na região sudeste do Brasil, este tipo de dispersão, característico da agricultura tradicional, tem ampliado a base genética de culturas manejadas em sistemas agrícolas (PERONI et al., 2007). Estas áreas são caracterizadas por realizar constantes trocas entre os locais de cultivo, estimulando a dispersão de indivíduos e, consequentemente, possibilitando maior fluxo gênico entre as populações mantidas neste sistema agrícola. Além disso, os agricultores tendem a manter alta variabilidade inter e intra-específica (BRESSAN et al., 2005; VEASEY et al., 2008). Esses fatores têm contribuído para a manutenção e amplificação da diversidade genética de muitas espécies cultivadas.

Seleção

A seleção é a ação natural ou artificial exercida em uma determinada população capaz de alterar suas frequências alélicas, pelo fato de apenas alguns indivíduos contribuírem para a formação das gerações seguintes (FALCONER, 1987). Na seleção natural, as populações são direcionadas no sentido de tornaremse mais adaptadas ao ambiente no qual estão inseridas, decorrente do sucesso reprodutivo diferencial dos indivíduos (HANCOCK, 2005). Na artificial, a seleçãoé realizada de forma intencional ou inconsciente, visando à melhoria das características vegetais para os interesses e necessidades humanas. Este processo, conhecido como domesticação, está diretamente relacionado à evolução das plantas cultivadas (HARLAN, 1992).

As espécies domesticadas, quando comparadas aos seus ancestrais selvagens, apresentam uma série de modificações genéticas, morfológicas, fisiológicas e fenológicas resultantes da seleção (FULLER, 2007). Entre essas modificações, conhecidas como síndromes de domesticação, observam-se a perda de dormência e aumento no tamanho das sementes, mecanismo de dispersão ineficiente, hábito de crescimento determinado, arquitetura mais compacta, bem como redução de substâncias tóxicas, entre outros (PURUGGANAN \& FULLER, 2009). O milhoé um bom exemplo das modificações ocorridas durante a domesticação, pois, quando comparado com o teosinto, 
espécie ancestral, apresenta maior dificuldade na dispersão natural da semente, pois os grãos estão aderidos ao sabugo e são envolvidos pela palha (DOEBLEY et al., 2006). Assim como no milho, o arroz, além das alterações estruturais e reprodutivas ocorridas ao longo da domesticação, tem sofrido pressão de seleção pelo homem para tornar os grãos mais atraentes, com relação ao tamanho, forma, cor, fragrância e conteúdo de amilose do grão (KOVACH et al., 2007). Nesse mesmo contexto, o aumento do teor de proteína bruta no grão de aveia para a alimentação humana tem sofrido constante ação do homem, visto que a maioria dos materiais selvagens possui baixo teor de proteína (MATIELLO et al., 1997). Outro exemplo seria o do tomateiro (Solanum lycopersicum), cujos frutos sofreram um incrível aumento no tamanho ao longo de sua domesticação, quando comparado com seu ancestral mais próximo S. lycopersicum var cerasiforme. Esse processo no tomateiro, envolveu principalmente a mutação e seleção do QTL (loco de característica quantitativa) $f w 2.2$, o qual é um loco chave para a evolução do tamanho do fruto da cultura (FRARY et al., 2000) (Tabela 1).

Devido às características envolvidas no processo de domesticação serem principalmente quantitativas, o uso de técnicas moleculares, sobretudo o mapeamento de locos de caracteres quantitativos, tem auxiliado nos estudo da evolução das espécies vegetais, tanto na ação destes genes envolvidos na domesticação quanto nos efeitos da seleção neste processo (YAMASAKI et al., 2007). A análise comparativa do polimorfismo de nucleotídeos dos genes relacionados à domesticação tem possibilitado determinar em que medida a seleção está atuando em todo o genoma. Esta análise, denominada selective sweep, permite observar os nucleotídeos que foram eliminados em função da elevada pressão de seleção nos materiais selvagens. No milho, o gene teosinte branched $l\left(\mathrm{~Tb}_{l}\right)$ foi identificado num QTL que atua no controle da dormência dos meristemas apicais e axilares, sendo ativo em seu ancestral selvagem, o teosinto (Zea mays ssp. parviglumis) (DOEBLEY, 2004). O gene $Q$, envolvido na domesticação do trigo, afeta um conjunto de características, incluindo a forma alongada do trigo selvagem ou compacta como nas espécies cultivadas, bem como a estrutura de inflorescência e época de floração (SIMONS et al., 2006). O shattering $4\left(\mathrm{Sh}_{4}\right)$ é um QTL que controla a liberação de sementes da planta no arroz selvagem ou permite a sua maior fixação, como no arroz cultivado (KOVACH et al., 2007). A comparação genômica das plantas cultivadas com os seus respectivos parentais selvagens permite compreender que a evolução do genoma está relacionada à pressão de seleção em determinadas regiões do material genético, responsáveis pela expressão dos caracteres relacionados à domesticação (BURKE et al., 2007).

Deriva genética

A deriva genética, definida como a imprevisibilidade de variação nas frequências alélicas em uma população de tamanho reduzido, pode ocorrer tanto em populações naturais quanto em espécies cultivadas (FUTUYMA, 2006). Em relação às plantas cultivadas, a deriva genética pode ser representada praticamente de duas formas: efeito do fundador, quando a domesticação ocorre fora do seu centro de origem, geralmente devido ao fato de uma amostra de poucos indivíduos ser levada para colonizar outra região e; gargalo de garrafa (bottleneck), quando o tamanho de uma população é reduzido drasticamente devido ao processo de seleção feito pelo homem, sendo que sua recomposição é feita a partir de poucos indivíduos e uma quantidade restrita de alelos (HANCOCK, 2004).

Em geral, a magnitude dos efeitos da deriva é mais forte quando a domesticação de uma planta ocorre fora do seu centro de origem, pois a troca de alelos com espécies selvagens torna-se inexistente. Esse efeito é mais pronunciado ainda em espécies autógamas, pois a endogamia, ao eliminar alelos deletérios por seleção natural ou artificial, acaba também eliminando alelos não deletérios que estão ligados a estes. Este é o exemplo do tomateiro (Solanum lycopersicum), planta autógama, domesticada no México, fora de seu centro de origem na América do Sul, no qual a principal consequência foi o estreitamento da base genética da cultura (MILLER \& TANKSLEY, 1990), tornando-a vulnerável ao ataque de pragas e doenças, além da fragilidade a ambientes estressantes. Processo semelhante observa-se na soja (Glycine max), já que poucos acessos foram trazidos da Ásia e introduzidos na América do Norte, no período de 1947 a 1988 (HYTEN et al., 2006). Já no caso do milho (Zea mays), tal efeito foi menos pronunciado, uma vez que esta é uma espécie alógama, a qual foi domesticada no seu próprio centro de origem. Isso fez com que o milho preservasse perto de $75 \%$ da sua diversidade genética original, quando comparado com seus parentais selvagens, Zea parviglumis e Zea luxurians (EYREWALKER et al., 1998).

Várias são as culturas que demonstram perda de diversidade genética devido a sucessivos gargalos de garrafa, tais como café (Coffea arabica) (LÓPEZGARTNER et al., 2009), algodão (Gossypium hirsutum) (IQBAL et al., 2001), tomateiro(Solanum lycopersicum) 
(SAN-SAN-YI et al., 2008), grão-de-bico (Cicer arietinum) (ABBO et al., 2003), entre outras (Tabela 1). Tal processo também foi importante na domesticação de espécies arbóreas como a teca (Tectona grandis) (VARGHESE et al., 2006) e de plantas daninhas que coevoluiram com as plantas cultivadas, como é o caso de Lythrum salicaria, a qual foi introduzida nos EUA a partir da Europa (ECKERT et al., 1996). Estimativas da intensidade dessa perda de diversidade genética encontrada nos ancestrais selvagens variam consideravelmente, desde $80 \%$ no milho (WRIGHT \& GAUT, 2005) para 40-50\% no girassol (LIU \& BURKE, 2006) e 10-20\% no arroz (ZHU et al., 2007).

Em contraste, é possível, em menor escala, fazer o caminho contrário ao processo de deriva, através da busca de novos alelos em espécies selvagens e variedades crioulas. Vários programas de melhoramento genético buscam novos alelos em espécies selvagens, principalmente aqueles relacionados a tolerâncias a diversas pragas e doenças. Esse é o caso de espécies como o trigo (Triticum aestivum) (REIF et al., 2005), o arroz (KOVACH \& McCOUCH, 2008) e tomateiro (PINO-NUNES et al., 2009), às quais vem sendo reincorporados vários novos alelos a partir de cruzamentos com espécies relacionadas.

\section{CONCLUSÃO}

Conclui-se com esta revisão que a origem e a domesticação das plantas cultivadas estiveram diretamente relacionadas, ao longo de suas histórias evolutivas, com os processos evolutivos abordados (mutação, hibridação, migração, seleção e deriva genética), que têm atuado no sentido de manter, aumentar ou mesmo diminuir a diversidade genética das espécies cultivadas. São vários os exemplos (Tabela 1) de como esses processos influenciaram no aparecimento de novas espécies de plantas, assim como de novas variedades dentro de espécies domesticadas. É bom lembrar que a divisão desses processos foi feita de forma a tornar sua compreensão mais clara, uma vez que todos eles ocorrem de forma simultânea, diferindo somente na magnitude da importância de cada fenômeno para a domesticação das diferentes espécies cultivadas.

\section{REFERÊNCIAS}

ABBO, S. et al. Evolution of cultivated chickpea: four bottlenecks limit diversity and constrain crop adaptation. Functional Plant Biology, v.30, n.10, p.1081-1087, 2003. Disponível em: <http:/ /www.publish.csiro.au/?act=view_file\&file_id=FP03084.pdf $>$. Acesso em: 19 abr. 2011. doi: 10.1071/FP03084.
AGUILAR-MELÉNDEZ, A. et al. Genetic diversity and structure in semiwild and domesticated chiles (Capsicum annum; Solanaceae) from Mexico. American Journal of Botany, v.96, p.1190-1202, 2009. Disponível em: <http://www.amjbot.org/cgi/reprint/96/6/ 1190 ? maxtoshow $=$ \&hits $=10 \&$ RESULTFORMAT $=$ \&author $1=$ Aguilar melendez $\&$ andorexacttitle $=$ and $\&$ a ndorexacttitleabs $=$ and $\&$ andore c t f u $11 \mathrm{tex} \mathrm{t}=$ a n d \& s e a r c hid $=1 \&$ F I R S T IN D E $\mathrm{X}=0$ \&sortspec=relevance\&resourcetype $=$ HWCIT $>$. Acesso em: 19 abr. 2011. doi: 10.3732/ajb.0800155.

ANTHONY, F. et al. The origin of cultivated Coffea arabica L. varieties revealed by AFLP and SSR markers. Theoretical and Applied Genetics, v.104, p.894-900, 2002. Disponível em: <http://www.springerlink.com/content/4r9txcxh05211 gkk/ fulltext.pdf $>$. Acesso em: 19 abr. 2011. doi: 10.1007/s00122001-0798-8.

ARNOLD, M.L. Natural hybridization and the evolution of domesticated pest and disease organisms. Molecular Ecology, v.13, p.997-1007, 2004. Disponível em: <http:// onlinelibrary.wiley.com/doi/ $10.1111 /$ j. 1365 294X.2004.02145.x/pdf>. Acesso em: 19 abr. 2011. doi: 10.1111/j.1365-294X.2004.02145.x.

BELLWOOD, P. First farmers: the origins of agricultural societies. Blackwell, Malden, Mass, 2005. 360p.

BRAMMER, S.P. et al. A potencialidade de Agropyron, espécie afim ao trigo cultivado, como fonte de introgressão de genes agronomicamente importantes. Passo Fundo: Embrapa Trigo, 2001. 8p. (Embrapa Trigo Documentos online: 8 )

BRESSAN, E.A. et al. Collecting yam (Dioscorea spp.) and sweet potato (Ipomoea batatas) germplasm in traditional agriculture smallholdings in the Vale do Ribeira, São Paulo, Brazil. Plant Genetic Resources Newsletter, v.144, p.8-13, 2005. Disponível em: <http://www2.bioversityinternational.org/publications/pgrnewsletter/ article.asp?lang=en\&id_article=2\&id_issue=144. Acesso em: 19 abr. 2011.

BRETON, C. et al. The origins of the domestication of the olive tree. Comptes Rendus Biologies, v.332, p.1059-1064, 2009. Disponível em: <http://www.sciencedirect.com/ science?_ob=MImg\&_imagekey=B 6X1F-4X5B P1K-1 $7 \&$ _cdi $=7241 \&$ \&user $=5674931 \&$ _pii $=S 1631069109001$ 899\&_origin $=$ search \&_zone $=$ rsit_list_item\&_coverDate $=12 \% 2 \mathrm{~F} 31 \% 2 \mathrm{~F} 2009 \& \_\mathrm{sk}=996679987 \& \mathrm{wchp}=\mathrm{dGLzVzb}-$ zSkWA\&md5=eba93d1 e6ec7db84b13537b54527c910\&ie=/ sdarticle.pdf>. Acesso em: 19 abr. 2011. doi:10.1016/ j.crvi.2009.08.001.

BROWN, T.A. et al. The complex origin of domesticated crops in the Fertile Crescent. Trends in Ecology \& Evolution, v.24, p.103-109, 2009. Disponível em: <http://www.sciencedirect.com/ science?_ob=ArticleURL\&_udi=B6VJ1-4V7BG4J-3\&_user= $10 \&$ _coverDate $=02 \% 2 \mathrm{~F} 28 \% 2 \mathrm{~F} 2009 \&$ rdoc $=14 \&$ fmt $=$ high\&_orig=browse\&_origin=browse\&_zone=rslt_list_item\&_srch=docinfo(\%23 toc \%236081\%232009\%23999759997 $\% 23857162 \% 23 \mathrm{FLA} \% 23 \mathrm{disp} 1$ ay $\% 23 \mathrm{Vo} 1 \mathrm{ume}$

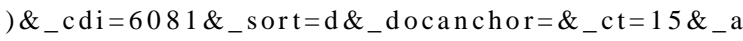
cct $=$ C000050221\&_version $=1 \& \_u r l$ Version $=0 \& \_u$ serid $=10$ $\& \mathrm{md} 5=$ f9c947ffec6b95d467e20e9b72f1e90a\&searchtype $=\mathrm{a}>$. Acesso em: 19 abr. 2011. doi:10.1016/j.tree.2008.09.008. 
BURKE, J.M. et al. Crop evolution: from genetics to genomics. Current Opinion in Genetics \& Development, v.17, p.525532, 2007. Disponível em: <http://www.sciencedirect.com/ science?_ob=ArticleURL\&_udi=B 6VS 0-4PYJDYK-

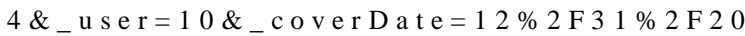
$07 \&_{-}$rdoc $=13 \&_{-}$fmt $=$high \&_orig $=$browse \& _origin $=$ browse\&_zone $=$ rslt_list_item \&_srch $=$ doc info(\%23 toc\%236248\%232007\%23999829993\%2 $3675686 \% 23 \mathrm{FLA} \% 23 \mathrm{disp} 1$ a y $\% 23 \mathrm{Volum}$ e) \&_cdi=6248\&_sort=d\&_docanchor $=\& \_c t=17 \& \_a c c t=C 00005022$ $1 \&$ \&ersion $=1 \&$ \&urlVersion $=0 \& \_u s e r i d=10 \& \mathrm{md} 5=92196 \mathrm{ad} 8 \mathrm{f} 7 \mathrm{c}$ 2bbe51648d0d0ea366fb3\&searchtype=a>. Acesso em: 20 abr. 2011. doi: 10.1016/j.gde.2007.09.003.

BURTON, W.G. The potato. Wageningen: Veenman and Zonen, 1966. $153 \mathrm{p}$.

CHANDERBALI, A.S. et al. Phylogeny and historical biogeography of Lauraceae: evidence from chloroplast and nuclear genomes. Annals of the Missouri Botanical Garden, v.88, p.104-134, 2001. Disponível em: <http:// www.biodiversitylibrary.org/item /86343\#page/106/mode/1up>. Acesso em: 20 abr. 2011.

CRESTANI, M. et al. Das Américas para o Mundo - origem, domesticação e dispersão do abacaxizeiro. Ciência Rural, v.40, p.1473-1483, 2010. Disponível em: <http://www.scielo.br/ $\mathrm{pdf} / \mathrm{cr} / \mathrm{v} 40 \mathrm{n} 6 / \mathrm{a} 620 \mathrm{cr} 2584$.pdf $>$. Acesso em: 20 abr. 2011. doi: 10.1590/S0103-84782010000600040.

CTENAS, M.L.B.; QUAST, D. Abacaxi. In: CTENAS, A.C. et al. (Eds.). Frutas das terras brasileiras. São Paulo: C2, 2000. p.41-45.

DALTON, R. Mexico's transgenic maize under fire. Experimental planting scheme has insufficient controls to prevent gene flow to native crops, critics say. Nature, v.462, p.404, 2009. Disponível em:<http://www.nature.com/news/ 2009/091125/pdf/462404a.pdf>. Acesso em: 20 abr. 2011. doi: $10.1038 / 462404 \mathrm{~b}$.

DIAMOND, J.M. Evolution, consequences and future of plant and animal domestication. Nature, v.418, p.700-707, 2002. Disponível em: <http://www.nature.com/nature/ journal/v418/ n6898/pdf/nature01019.pdf. Acesso em: 20 abr. 2011. doi:10.1038/nature01019.

DIAMOND, J.M.; BELLWOOD, P. Farmers and their languages: the first expansions. Science, v.300, p.597-603, 2003. Disponível em: <http://www.sciencemag.org/content/ 300/5619/ 597.full.pdf $>$. Acesso em: 20 abr. 2011. doi:10.1126/ science. 1078208 .

DOEBLEY, J.F. The genetics of maize evolution. Annual Review of Genetics, v.38, p.37-59, 2004. Disponível em: <http://www.annualreviews.org/doi/pdf/10.1146/ annurev.genet.38.072902.092425>. Acesso em: 20 abr. 2011. doi: 10.1146/annurev.genet.38.072902.092425.

DOEBLEY, J.F. et al. The molecular genetics of crop domestication. Cell, v.127, p.1309-1321, 2006. Disponível em: 〈http://www.cell.com/abstract/S0092-8674(06)01592-3>. Acesso em: 20 abr. 2011. doi:10.1016/j.cell.2006.12.006.
DUPUTIÉ, A. et al. Natural hybridization between a clonally propagated crop, cassava (Manihot escultenta Crantz). Molecular Ecology, v.16, p.3025-3038, 2007. Disponível em: <http://onlinelibrary.wiley.com/doi/10.1111/j.1365294X.2007.03340.x/pdf>. Acesso em: 19 abr. 2011. doi: 10.1111/j.1365-294X.2007.03340.x.

ECKERT, C.G. et al. Genetic drift and founder effect in native versus introduced populations of an invading plant, Lythrum salicaria (Lythraceae). Evolution, v.50, p.1512-1519, 1996. Disponível em: <http://www.jstor.org/stable/2410888>. Acesso em: 20 abr. 2011 .

ELLSTRAND, N.C. et al. Gene flow and introgression from domesticated plants into their wild relatives. Annual Review of Ecology, Evolution and Systematics, v.30, p.539-563, 1999. Disponível em: <http://www.annualreviews.org/doi/pdf/ 10.1146/annurev.ecolsys. 30.1.539>. Acesso em: 20 abr. 2011. doi: 10.1146/annurev.ecolsys.30.1.539.

EYRE-WALKER, A. et al. Investigating the bottleneck leading to the domestication of maize. Proceedings of the National Academy of Sciences, v.95, p.4441-4446, 1998. Disponível em: <http://www.pnas.org/content/95/8/4441.full.pdf+html>. Acesso em 20 abr. 2011.

FALCONER, D.S. Introdução à genética quantitativa. Viçosa: UFV, 1987. 279p.

FERNANDES, M.I.B.M. et al. Fatores responsáveis pela desuniformidade varietal no trigo Triticum aestivum (L.) Thell e o papel da instabilidade cromossômica. Pesquisa Agropecuária Brasileira, v.26, p.353-369, 1991. Disponível em: <http://webnotes.sct.embrapa.br/pdf/pab1991/marco/ pab10_mar_91.pdf >. Acesso em: 20 abr. 2011.

FRARY, A. et al. Fw2.2: a quantitative trait locus key to the evolution of tomato fruit size. Science, v.289, p.85-88, 2000. Disponível em: <http://www.sciencemag.org/content/289/5476/ 85>. Acesso em: 20 abr. 2011. doi: 10.1126/ science.289.5476.85

FULLER, D.Q. Contrasting patterns in crop domestication and domestication rates: recent archaeobotanical insights from the Old World. Annals of Botany, v.100, p.903-924, 2007. Disponível em: <http://aob.oxfordjournals.org/content/100/5/ 903.full.pdf+html>. Acesso em: 20 abr. 2011. doi: 10.1093/ $\mathrm{aob} / \mathrm{msm} 048$.

FUTUYMA, D.J. Evolutionary biology. Sunderland: Sinauer Associates, 2006. 763p.

GEPTS, P.; PAPA, R. Possible effects of (trans) gene flow from crops on the genetic diversity from landraces and wild relatives. Environmental Biosafety Research, v.2, p.89103, 2003. Disponível em: <http://www.ncbi.nlm.nih.gov/ pubmed/15612275>. Acesso em: 20 abr. 2011.

HAMARICK, J.L.; NASON, J.D. Consequences of dispersal in plants. In: RHODES, O.E. et al. Population dynamic in ecological space and time. Chicago: University of Chicago, 1996. p.203-236.

HANCOCK, J.F. Plant evolution and the origin of crop species. Wallingford: CABI, 2004. 313p. 
HANCOCK, J.F. Contributions of domesticated plant studies to our understanding of plant evolution. Annals of Botany, v.96, p.953-963, 2005. Disponível em: <http:// aob.oxfordjournals.org/content/96/6/953.full.pdf + html $>$. Acesso em: 20 abr. 2011. doi: 10.1093/aob/mci259.

HARLAN, J.R. Crops and man. Madison: American Society of Agronomy, 1992. 284p.

HOVAV, R. et al. Parallel domestication, convergent evolution and duplicated gene recruitment in allopolyploid cotton. Genetics, v.179, p.1725-1733, 2008. Disponível em: <http:/ /www.genetics.org/cgi/reprint/179/3/1725>. Acesso em: 20 abr. 2011. doi: $10.1534 /$ genetics.108.089656.

HYTEN, D.L. et al. Impacts of genetic bottlenecks on soybean genome diversity. Proceedings of the National Academy of Sciences, v.103, p.16666-16671, 2006. Disponível em: <http://www.pnas.org/content/103/45/16666.full.pdf+html>. Acesso em: 20 abr. 2011. doi: 10.1073/pnas.0604379103.

IQBAL, M.J. et al. A genetic bottleneck in the "evolution under domestication' of upland cotton Gossypium hirsutum L. examined using DNA fingerprinting. Theoretical and Applied Genetics, v.103, p.547-554, 2001. Disponível em: <http:// www.springerlink.com/content/9bgb 2 y 14 qe $270 \mathrm{wr} /$ fulltext.pdf $>$. Acesso em: 20 abr. 2011. doi: 10.1007/ PL00002908.

ISHIY, T. et al. Rice mutant cultivar SCS114 Andosan. Plant Mutation Report, v.1, p.25, 2006. Disponível em: <http:// www-pub.iaea.org/MTCD/publications/PDF/Newsletters/PMR01-02.pdf>. Acesso em: 20 abr. 2011.

JASKANI, M.J. et al. Induction and characterization of tetraploid watermelon. Journal of the Korean Society Horticultural Science, v.45, p.60-65, 2004.

KIKUCHI, S. et al. Effects of heavy-ion beams on chromosomes of common wheat, Triticum aestivum. Mutation Research, v.669, p.63-66, 2009. Disponível em: <http://www.sciencedirect.com/ science?_ob=MImg\&_imagekey=B6T2C4W8VW8R 13 \&_cdi=4915\&_user $=5674931 \&$ \&ii $=$ S 0027510709 $001614 \&$ \&origin $=$ gateway $\&$ _coverDate $=10 \% 2 \mathrm{~F} 02 \% 2 \mathrm{~F} 20$ $09 \&$ \&k $=993309998 \&$ view $=\mathrm{c} \& \mathrm{wch} \mathrm{p}=\mathrm{dGLbVtbzSkWA \& md5}$ $=3 \mathrm{c} 85 \mathrm{a} 24 \mathrm{fe} 0547 \mathrm{c} 223 \mathrm{f} 9 \mathrm{a} 8 \mathrm{ca} 213270906 \& \mathrm{ie}=/$ sdarticle.pdf $>$. Acesso em: 20 abr. 2011. doi: 10.1016/j.mrfmmm.2009.05.001.

KIM, S. et al. Gold color in onions (Allium cepa): a natural mutation of the chalcone isomerase gene resulting in a premature stop codon. Molecular Genetics and Genomics, v.272, p.411-419, 2004. Disponível em: <http://www.springerlink.com/ content/yfyj 5844d0m02mxw/fulltext.pdf $>$. Acesso em: $20 \mathrm{abr}$. 2011. doi: 10.1007/s00438-004-1076-7.

KIMBER, G. Basis of the diploid-like meiotic behaviour of polyploid cotton. Nature, v.191, p.98-100, 1961. Disponível em: <http://www.nature.com/nature/journal/v191/ n4783/abs/ 191098a0.html>. Acesso em: 20 abr. 2011. doi: 10.1038/ $191098 \mathrm{a} 0$.

KOVACH, M.J.; McCOUCH, S.R. Leveraging natural diversity: back through the bottleneck. Current Opinion in Plant Biology, v.11, p.193-200, 2008. Disponível em: <http:// w w w. s c i e $n$ c e d i r e c t c c o science?_ob=MImg\&_imagekey=B6VS44RY 91XD 1
$9 \&$ \& di $=6252 \&$ _user $=5674931 \&$ \& ii $=$ S 1369526608 $000186 \&$ origin $=$ gateway\&_coverDate $=04 \% 2 \mathrm{~F} 30 \% 2 \mathrm{~F} 2008 \&$ \&sk $=99$ $9889997 \&$ vi e w $=\mathrm{c} \& \mathrm{w} \mathrm{chp}=\mathrm{dGLbVzbzSk} \mathrm{W} \mathrm{b} \&$ $\operatorname{md} 5=827$ a 8 f 9765062 c 6 adecf 4 ed 270 ed $2925 \&$ ie $=/$ sdarticle.pdf $>$. Acesso em: 20 abr. 2011. doi: 10.1016/ j.pbi.2007.12.006.

KOVACH, M.J. et al. New insights into the history of rice domestication. Trends in Genetics, v.23, p.578-587, 2007. Disponível em: <http://www.sciencedirect.com/science? _o b = M Img \&_image k e y = B 6 T C Y 4 R 05 H Y K 19 $\&_{-}$cdi=5183\&_user=5674931\&_pi i=S 01689 $52507003046 \&$ origin $=$ gateway \&_coverDate $=11 \% 2 \mathrm{~F} 30 \%$ $2 \mathrm{~F} 2007 \&$ \&k $=999769988 \&$ view $=\mathrm{c} \& \mathrm{w} \mathrm{chp}=\mathrm{dGLbVtbzSkz}$ $\mathrm{k} \& \mathrm{md} 5=\mathrm{fd} 5 \mathrm{~d} 0 \mathrm{da} 9 \mathrm{a} 8786 \mathrm{e} 4 \mathrm{dc} 64391 \mathrm{e} 6 \mathrm{~b} 60 \mathrm{f0} 28 \mathrm{c} \& \mathrm{ie}=/$ sdarticle.pdf>. Acesso em: 20 abr. 2011. doi: 10.1016/ j.tig.2007.08.012.

LADIZINSKY, G. Plant evolution under domestication. London: Kluwer Academic, 1998. 254p.

LATADO, R.R. et al. Mutantes de laranja-'pêra' com número reduzido de sementes, obtidos através de mutações induzidas. Revista Brasileira de Fruticultura, v.23, p.339-344, 2001. Disponível em: 〈http://www.scielo.br/pdf/rbf/v23n2/7978.pdf〉. Acesso em: 20 abr. 2011. doi: 10.1590/S010029452001000200028 .

LIU, A.; BURKE, J.M. Patterns of nucleotide diversity in wild and cultivated sunflowers. Genetics, v.173, p.321-330, 2006. Disponível em: <http://www.genetics.org/cgi/reprint /173/1/ 321 ? $\mathrm{maxt}$ os how $=\& \mathrm{hit} \mathrm{s}=10 \& \mathrm{RESULTF}$ $\mathrm{ORMAT}=1 \&$ a nd orexact t i $1 \mathrm{e}=\mathrm{phrase} \&$ a n dorexacttitleabs $=$ phrase $\&$ andore $x$ actfullte $\mathrm{xt}=\mathrm{phrase}$ $\&$ se archid $=1 \&$ FIRST IN DEX $=0 \&$ sortspec $=$ date \& v olume $=173 \&$ firstpage $=321 \&$ resourcetype $=$ HWCIT $>$. Acesso em: 20 abr. 2011. doi: 10.1534/genetics.105.051110.

LÓPEZ-GARTNER, G. et al. Analysis of genetic structure in a sample of coffee (Coffea arabica L.) using fluorescent SSR markers. Tree Genetics and Genomes, v.5, p.435-446, 2009. Disponível em: <http://www.springerlink.com/content/ j0q51761753810um/fulltext. html>. Acesso em: 25 abr. 2011. doi: $10.1007 / \mathrm{s} 11295-008-0197-2$.

LU, B.; YANG, C. Gene flow from genetically modified rice to its wild relatives: assessing potential ecological consequences. Biotechnology Advances, v.27, p.1083-1091, 2009. Disponível em: <http://www.sciencedirect.com/ science?_ob=ArticleURL\&_udi=B 6 T 4 X-4 W B C1PT$7 \&$ _user $=5674931 \&$ \&coverDate $=12 \% 2 \mathrm{~F} 31 \% 2 \mathrm{~F} 2009 \&$ \&doc $=$ $1 \& \_f m t=h i g h \&$ orig=gateway\&_origin=gateway\&_sort $=$ d\&_d ocanchor $=\&$ view $=c \& \_s e a r c h S t r I d=1729954171 \& \_$rerunOrigin $=$google \& _acct $=$ C000049650\&_version $=1$ \&_urlVersion $=0$ \&_userid $=56749$ $31 \& \operatorname{md} 5=\mathrm{e} 7487794 \mathrm{~b} 63 \mathrm{efd} 0 \mathrm{~d} 30 \mathrm{dc} 6 \mathrm{bad} 45810166 \&$ searchtype $=\mathrm{a}>$. Acesso em: 25 abr. 2011. doi: 10.1016/j.biotechadv.2009.05.018.

MEDINA, J.C. A cultura do abacaxi. In: MEDINA, J.C. et al. Frutas tropicais 2. São Paulo: Canton, 1978. p.6-68.

MAGNUSSEN, L.S.; HAUSER, T.P. Hybrids between cultivated and wild carrots in natural populations in Denmark. Heredity, v.99, p.185-192, 2007. Disponível em: <http:// www.nature.com/hdy/journal/v99/n2/full/6800982a.html>. Acesso em: 25 abr. 2011. doi: 10.1038/sj.hdy.6800982. 
MALLET, J. Hybrid speciation. Nature, v.446, p.279-283, 2007. Disponível em: <http://www.nature.com/nature/journal/ v446/n7133/pdf/nature05706.pdf>. Acesso em: 20 abr. 2011. doi:10.1038/nature05706.

MATIELLO, R.R. et al. Variabilidade genética para teor de proteína bruta em grãos de aveia. Ciência Rural, v.27, p.183187, 1997. Disponível em: <http://www.scielo.br/pdf/cr/v27n2/ a02v27n2.pdf>. Acesso em: 20 abr. 2011. doi: 10.1590/S010384781997000200002 .

MATSUOKA, Y. et al. A single domestication for maize shown by multilocus microsatellite genotyping. Proceedings of the National Academy of Sciences, v.99, p.6080-6084, 2002. Disponível em: <http://www.pnas.org/content/99/9/ 6080.full.pdf+html>. Acesso em: 20 abr. 2011. doi:10.1073/ pnas.052125199.

MILLER, J.C.; TANKSLEY, S.D. RFLP analysis of phylogenetic relationships and genetic variation in the genus Lycopersicon. Theoretical and Applied Genetics, v.80, p.437-448, 1990. Disponível em: <http://www.springerlink.com/content/ w290x81038054800/>. Acesso em: 25 abr. 2011. doi: 10.1007/ BF00226743.

PAPA, R. et al. The evolution of genetic diversity in Phaseolus vulgaris L. In: MOTLEY, T.J. Darwin's harvest: new approaches to the origins, evolution, and conservation of crop. New York: Columbia University, 2004. p.121-142.

PERONI, N. et al. Molecular differentiation, diversity, and folk classification of "sweet" and "bitter" cassava (Manihot esculenta) in Caiçara and Caboclo management systems (Brazil). Genetic Resources and Crop Evolution, v.54, p.1333-1349, 2007. Disponível em: <http://www.springerlink.com/content/ q3827ug3p234m67q/fulltext.pdf.> Acesso em: 20 abr. 2011. doi: $10.1007 / \mathrm{s} 10722-006-9116-2$.

PINO-NUNES, L.E. et al. Induced mutagenesis and natural genetic variation in tomato 'Micro-tom'. Acta Horticulturae, v.821, p.63-72, 2009.

PREDIERI, S.; ZIMMERMAN, R.H. Pear mutagenesis: In vitro treatment with gamma-rays and field selection for productivity and fruit traits. Euphytica, v.117, p.217-227, 2001. Disponível em: <http://www.springerlink.com/content/ m788800444g57x17/fulltext.pdf >. Acesso em: 20 abr. 2011. doi: 10.1023/A:1026594103277.

PURUGGANAN, M.D.; FULLER, D.Q. The nature of selection during plant domestication. Nature, v.457, p.843-848, 2009. Disponível em: <http://www.agri.ankara.edu.tr/fcrops/ 1289_SELECTION.pdf>. Acesso em: 20 abr. 2011. doi: $10.1038 /$ nature 07895 .

REIF, J. et al. Wheat genetic diversity trends during domestication and breeding. Theoretical and Applied Genetics, v.110, p.859-864, 2005. Disponível em: <http:// www.springerlink.com/content/7fg8xeuccvxqlcw4/fulltext.pdf $>$. Acesso em: 20 abr. 2011. doi: 10.1007/s00122-004-1881-8.
SAN-SAN-YI, S.A. et al. Potential loss of unique genetic diversity in tomato landraces by genetic colonization of modern cultivars at a noncenter of origin. Plant Breeding, v.127, p.189-196, 2008. Disponível em: <http://link.periodicos.capes.gov.br.ez72.periodicos.capes.gov.br/ sfxlc13?url_ver=Z39.88-2004\&url_ctx_fmt=infofi/ fmt:kev:mtx:ctx\&ctx_enc=info:ofi/enc:UTF-8\&ctx_ver=Z39.882004\&rfr_id=info:sid/sfxit.com:azlist\&sfx.ignore_date_thresh old=1\&rft.object_id=954925488804\&svc.fulltext=yes $>$. Acesso em: 20 abr. 2011. doi:10.1111/j.1439-0523.2007.01446.x.

SIMONS, K.J. et al. Molecular characterization on the major wheat domestication gene $Q$. Genetics, v.172, p.547-555, 2006. Disponível em: <http://www.genetics.org.ez72.periodicos.capes.gov.br/cgi/reprint/ 172/1/547>. Acesso em: 20 abr. 2011. doi: 10.1534/ genetics.105.044727.

SHOMURA, A. et al. Deletion in a gene associated with grain size increased yields during rice domestication. Nature Genetics, v.40, p.1023-1028, 2008. Disponível em: <http:// link.periodicos.capes.gov.br.ez72.periodicos.capes.gov.br/ sfxlc13?url_ver=Z39.88-2004\&url_ctx_fmt=infofi/ $\mathrm{fmt}: \mathrm{kev}: \mathrm{mtx}: \mathrm{ctx} \& \mathrm{ct} x_{-}$enc $=$info: ofi/enc:UTF$8 \& \mathrm{ctx}_{-}$ver $=$Z39.88-2004\&rfr_id=info:sid $/$ sfxit.com:azlist\&sfx.ignore_date_threshold $=1 \&$ rft.object_id $=954925598609 \&$ \&vc.fulltext $=$ yes $>$. Acesso em: 20 abr. 2011. doi:10.1038/ng.169.

SPOONER, D. M. et al. Extensive simple sequence repeat genotyping of potato landraces supports a major reevaluation of their gene pool structure and classification. Proceedings of the National Academy of Sciences, v.104, n.49, p. 1939819403, 2007. Disponível em: <http://www.pnas.org/content/ 104/49/19398.full.pdf+html>. Acesso em: 20 abr. 2011. doi: 10.1073/pnas.0709796104.

THIS, P. et al. Wine grape (Vitis vinifera L.) color associates with allelic variation in the domestication gene VvmybAl. Theoretical and Applied Genetics, v.114, p.723-730, 2007. Disponível em: <https://springerlink3.metapress.com/content/ $701127388 \mathrm{~g} 740501 / \mathrm{resource}-\mathrm{secured} /$ ? t a rget $=$ fu $11 \mathrm{text} . \mathrm{pdf} \& \mathrm{sid}=4 \mathrm{ghol} 0 \mathrm{j} 3 \mathrm{bfw} 0$ rwo 452 vsgid $3 p \& s h=w w w . s p r i n g e r l i n k . c o m>$. Acesso em: 20 abr. 2011. doi: 10.1007/s00122-006-0472-2.

VARGHESE, M. et al. Impact of fertility variation on gene diversity and drift in two clonal seed orchards of teak (Tectona grandis Linn. f.). New Forests, v.31, p.497-512, 2006. Disponível em: <https://springerlink3.metapress.com/content/ 1565 v 765 n $4532314 / \mathrm{res}$ ource-secured/ ? target $=$ full 11 ext.pdf \& sid $=4$ g ho 0 j 3 b f w 0 rwo452vsgid3p\&sh=www.springerlink.com>. Acesso em: 20 abr. 2011. doi: 10.1007/s11056-005-2178-8.

VEASEY, E.A. et al. Genetic diversity assessed with microsatellites in Brazilian sweetpotato (Ipomoea batatas (L.) Lam) landraces. Genetics and Molecular Biology, v.31, p.725-733, 2008. Disponível em: <http://www.scielo.br/pdf/ $\mathrm{gmb} / \mathrm{v} 31 \mathrm{n} 3 / \mathrm{a} 20 \mathrm{v} 31 \mathrm{n} 3 . \mathrm{pdf}>$. Acesso em: 20 abr. 2011. doi: 10.1590/S1415-47572008000400020. 
WEIRSUM, K.F. Indigenous exploitation and management of tropical forest resources: an evolutionary continuum in forestpeople interactions. Agriculture, Ecosystems and Environment, v.63, p.1-16, 1997. Disponível em: <http://

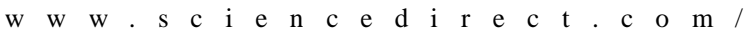
science?_ob=ArticleURL\&_udi=B6T3Y-3RHMRY 1 $1 \&$ _user $=10 \&$ \&coverDate $=05 \% 2$ F3 $1 \% 2$ F $1997 \&$ \&doc $=1 \&$ _fmt=high\&_orig=gateway\&_origin=gateway\&_sort=d\&_docanchor $=\&$ $\mathrm{v}$ i e w $=\mathrm{c} \&$ \& a c t $=\mathrm{C} 000050221 \&$ \& version $=1$ $\&$ urlVersion $=0 \&$ userid $=10 \&$ md $5=2$ bb 8 c 60 a 5 $6296 \mathrm{a} 390000 \mathrm{afd} 32 \mathrm{fc} 6 \mathrm{cbd} 7 \&$ searchtype $=\mathrm{a}>$. Acesso em: 20 abr. 2011. doi:10.1016/S0167-8809(96)01124-3.

WILLIAM, D.E. Columbian exchange: the role of analogue crops in the adoption and dissemination of exotic cultigens. In: GOODMAN, R. Encyclopedia of plant and crop science. New York: Marcel Dekker, 2004. p.292-296.
WRIGHT, S.I.; GAUT, B.S. Molecular population genetics and the search for adaptative evolution in plants. Molecular Biology and Evolution, v.22, p.506-519, 2005. Disponível em: <http:// mbe.oxfordjournals.org/content/22/3/506.full.pdf+html>. Acesso em: 20 abr. 2011. doi:10.1093/molbev/msi035.

YAMASAKI, M. et al. Genomic screening for artificial selection during domestication and improvement in maize. Annals of Botany, v.100, p.967-973, 2007. Disponível em: <http:// aob.oxfordjournals.org/content/100/5/967.full.pdf+html > Acesso em: 20 abr. 2011. doi:10.1093/aob/mcm173.

ZHU, Q. et al. Multilocus analysis of nucleotide variation of Oryza sativa and its wild relatives: severe bottleneck during domestication of rice. Molecular Biology and Evolution, v.24, p.875-888, 2007. Disponível em: <http:// mbe.oxfordjournals.org/content/24/3/875.full.pdf+html > . Acesso em: 20 abr. 2011. doi:10.1093/molbev/msm005. 